\title{
S6 Abbreviations, Naming, AND COINAGE
}

Generally, only the most reliable version is cited in the case of duplicate archival sources or multiple editions. In addition to the acronyms specified in the bibliography, the following abbreviations are used throughout the notes: Arm. (Armario), c. (carpeta, calaix, capítol), chap. (chapter), doc. (document/o), C (Cancillería Real), fol(s). (folio), leg. (legajo), no(s). (número), n (note), perg(s). (pergamí/pergamino), Reg. (Registre/o).

The names of individuals that appear in the chapters that follow generally reflect the linguistic cultures of their home regions, whenever distinguishable. For example, a Latin document referring to a certain "Jacobus" clearly deriving from the town of Salou, in Catalonia, would appear as Jaume, whereas a "Jacobus" from Zaragoza or Toledo would be named Jaime. Similarly, due to their dynasty's long-standing identification with Catalonia, the count-kings of Barcelona and Aragon have Catalonian naming (Alfons, Pere, Jaume, etc.). Catalano-Aragonese monarchs following the merger with Aragon are numbered according to Catalonian tradition: for example, Alfons I "El Cast" (r. 1154-96) and Pere I "El Catòlic" (r. 1196-1213). Generally, the names of individuals appear as spelled by scribes without diacritical marks. However, well-known Jewish or Muslim historical figures, such as Muhammad ibn Abī 'Āmir (al-Manșur) or ibn Hazm, appear in their standard printed forms. Place-names that are commonly anglicized will appear as such throughout the text: for example, Catalonia and Aragon, not Catalunya and Aragón. Lesser known place-names will appear in their native forms: for example, Lleida and Zaragoza. Terminology such as aljama, lleuda, pedatge, and prohoms will be defined or explained when first employed. Since there are relatively few of these terms, this book does not utilize a glossary.

Although this study does refer to various distinct types of coinage and seeks to show how coinage could serve as a political tool, a detailed understanding of the Iberian Peninsula's complicated history of coinage is not necessary to follow its argumentation. It will suffice to appreciate that a number of roughly equivalent silver solidus coins circulated throughout the realms of the Crown of Aragon. As was the case with all currencies, the purchasing 
power of these solidi varied from year to year, but each, nevertheless, was subject to the traditional Carolingian ratio of one pound to twenty solidi to twelve denarii. Similarly, although the morabetin coins mentioned throughout this book fluctuated in value, each was worth about nine Catalonian solidi, and three morabetins were roughly equal to five masmudines. ${ }^{1}$ 


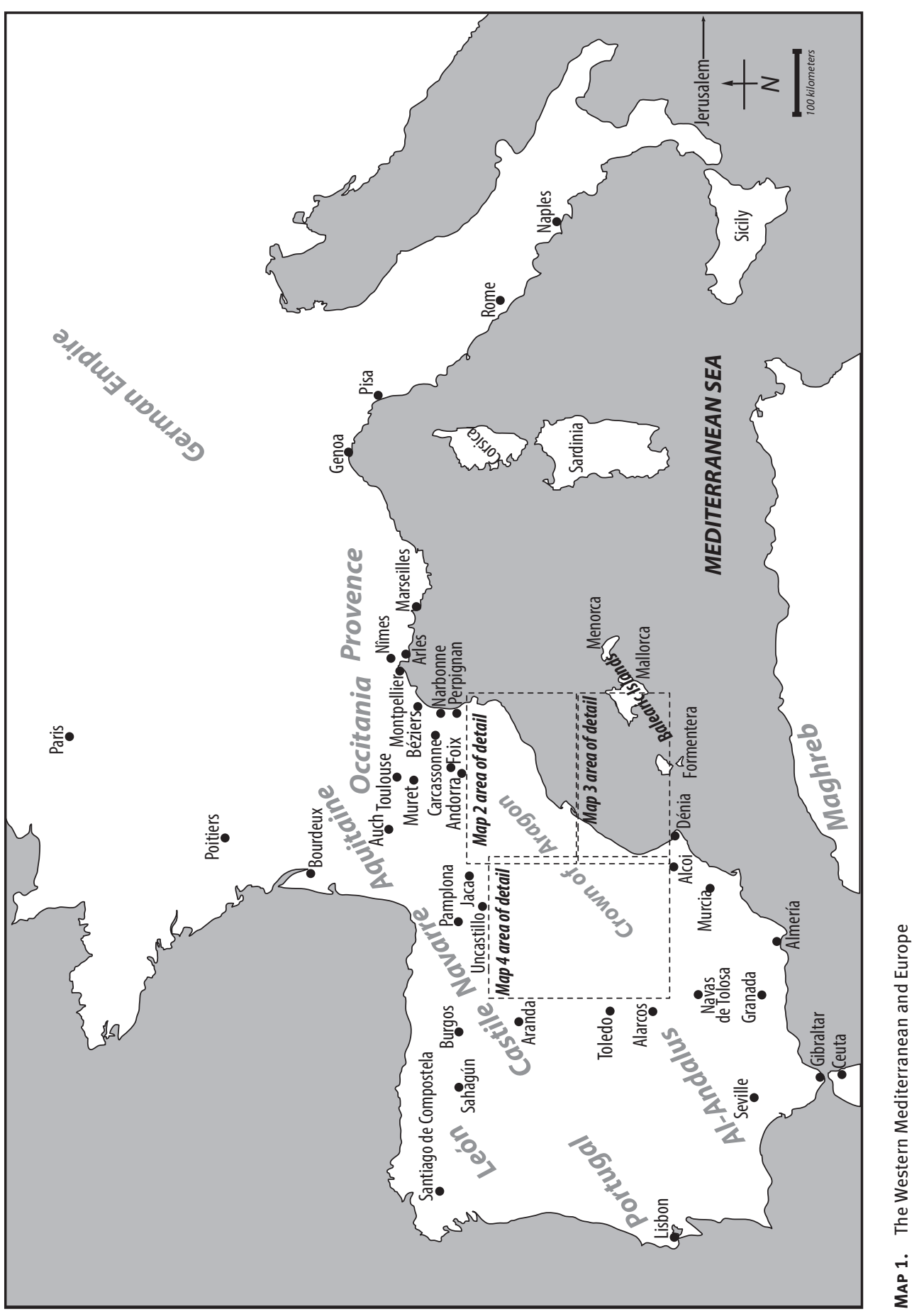




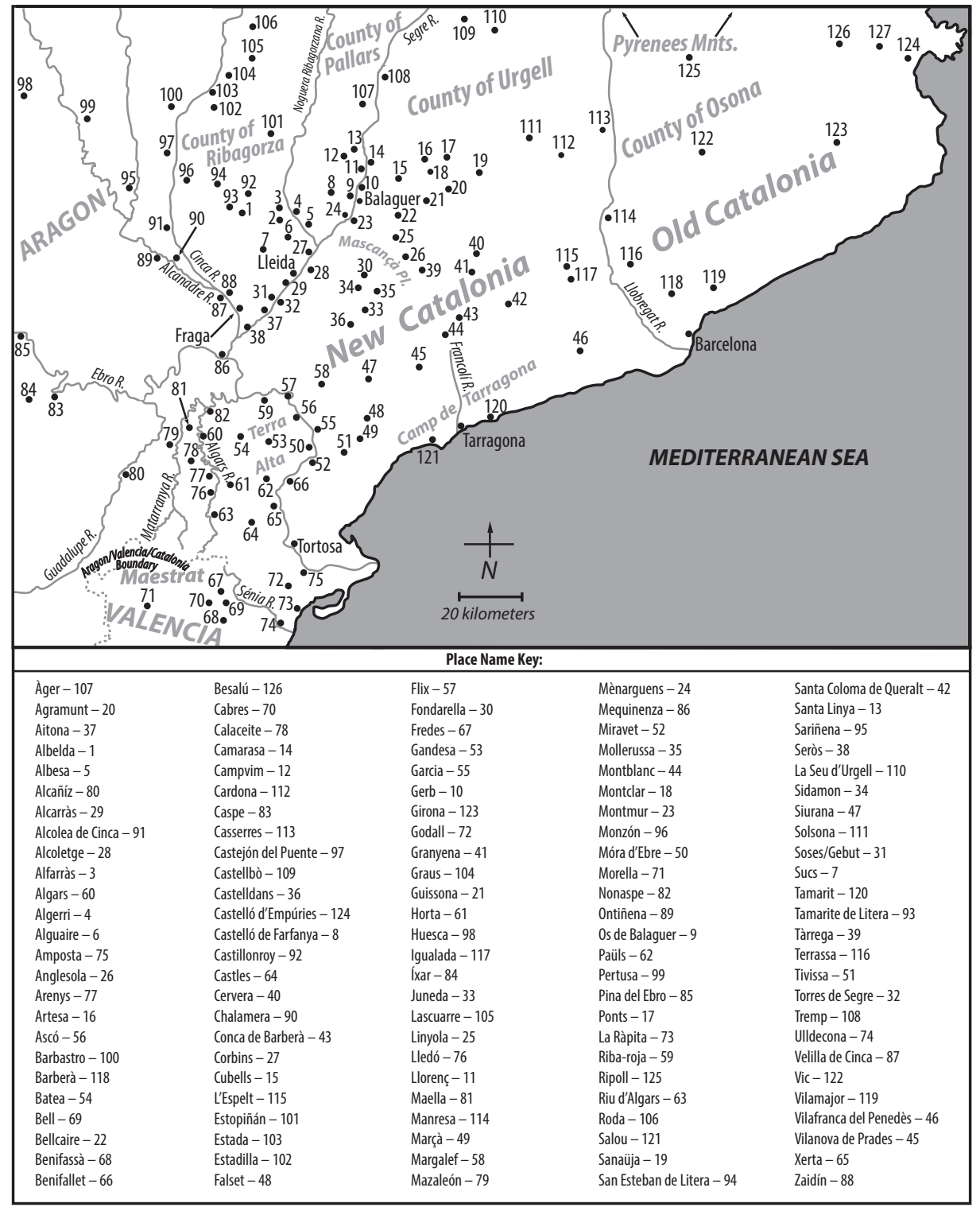

MAP 2. The Northeastern Crown of Aragon (detail from map 1) 


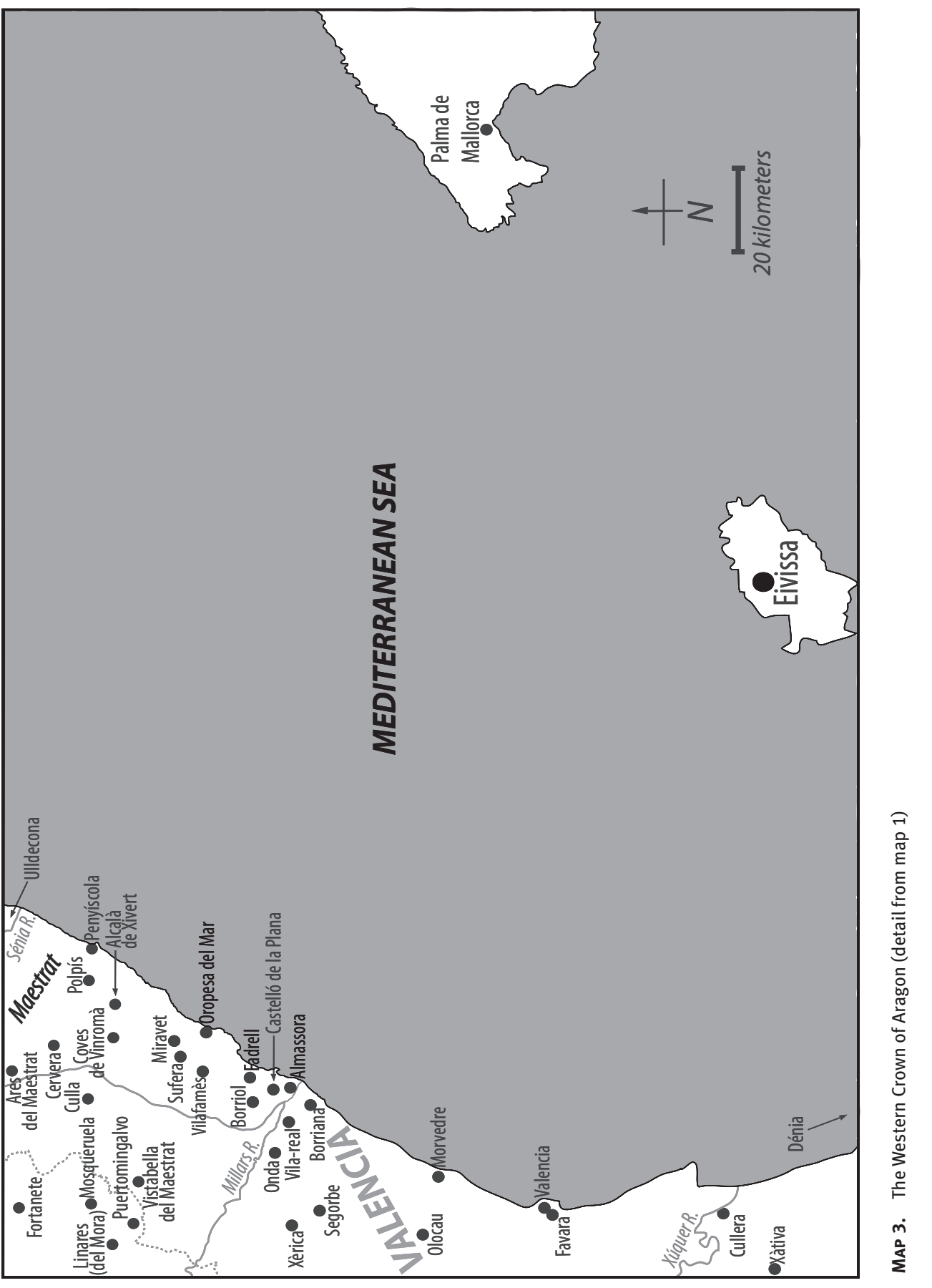




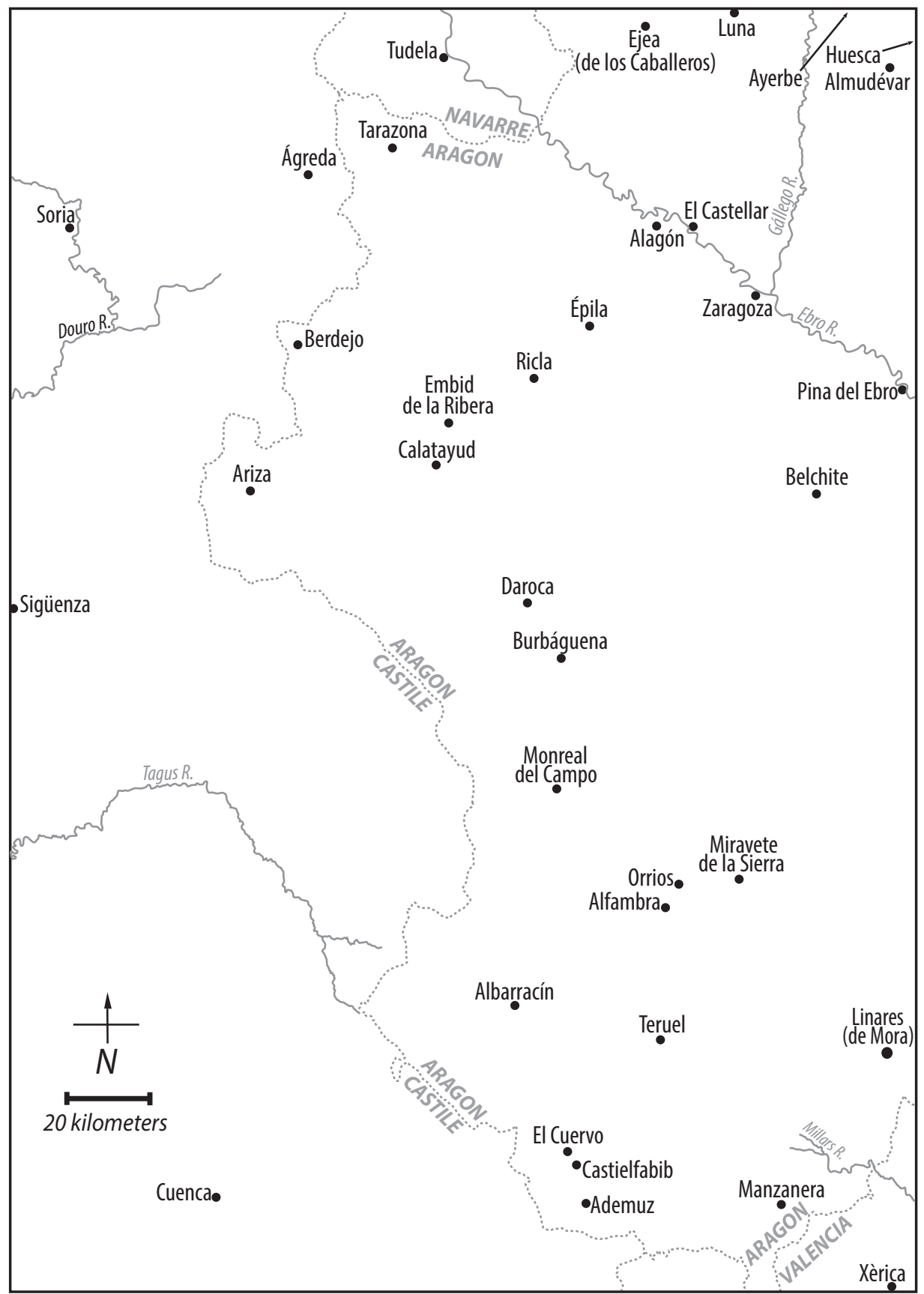

MAP 4. The Southeastern Crown of Aragon (detail from map 1) 
$\boldsymbol{s}$ VICTORY's SHADOW 
